\title{
MATRIZ ESTRATÉGICA DE INTELIGÊNCIA COMPETITIVA
}

\section{RESUMO}

O objetivo deste trabalho é propor uma matriz de relacionamento entre os conceitos de Acionabilidade - do modelo FAROUT de (Fleisher \& Bensoussan, 2003) - e Integridade -(Marcial, Costa, \& Curvelo, 2002) na Inteligência Competitiva (IC). Como metodologia, foi realizada uma pesquisa descritiva com um corte transversal único e aplicado a oito organizações escolhidas por conveniência do modelo, de setores diversos. Trata-se de um estudo qualitativo, setorial, exploratório de casos múltiplos. O Estudo produziu um modelo de análise associando acionabilidade e integridade de forma única. Como contribuição, foi elaborado uma proposta de matriz de relacionamento para verificar se as empresas possuem efetivamente uma área de IC e não de espionagem, especulação ou armazenagem; na matriz, os elementos constitutivos dos atributos da Acionabiliade e Integridade são medidos e classificados. Dentre as empresas pesquisadas, somente três delas demonstraram capacidade plena de construção de uma área de IC. A principal contribuição desse trabalho foi guardar similaridade com as ferramentas estratégicas tradicionais e associar dois conceitos es senciais à verificação da capacidade competitiva da empresa.

Palavras-chave: Inteligência Competitiva. Acionabilidade. Integridade.

\section{STRATEGIC MATRIX OF COMPETITIVE INTELLIGENCE}

\begin{abstract}
The objective of this work is to propose a matrix of relationship between the concepts of Actionability - the FAROUT model of (Fleisher \& Bensoussan, 2003) - and Integrity - (Marcial, Costa, \& Curvelo, 2002) in Competitive Intelligence (CI). As a methodology, a descriptive research was carried out with a single cross-section and applied to eight organizations chosen for convenience of the model, from different sectors. This is a qualitative, sectoral, exploratory study of multiple cases. The study produced a model of analysis combining actionability and integrity in a unique way. As a contribution, a proposal of a relationship matrix was prepared to verify if the companies effectively have a CI area and not espionage, speculation or storage; in the matrix, the constituent elements of the attributes of Action and Integrity are measured and classified. Among the companies surveyed, only three of them demonstrated full capacity to construct a CI area. The main contribution of this work was to keep similarity with the traditional strategic tools and to as sociate two es sential concepts to the verification of the competitive capacity of the company.
\end{abstract}

Keywords: Competitive Intelligence. Actionable. Integrity. 


\section{MATRIZ ESTRATÉGICA DE INTELIGÊNCIA COMPETITIVA}

\section{RESUMEN}

El objetivo de este trabajo es proponer una matriz de relación entre los conceptos de Accionabilidad - del modelo FAROUT de (Fleisher \& Bensoussan, 2003) - e Integridad - (Marcial, Costa, \& Curvelo, 2002) en la Inteligencia Competitiva (IC). Como metodología, se realizó una investigación descriptiva con un corte transversal único y aplicado a ocho organizaciones elegidas por conveniencia del modelo, de sectores diversos. Se trata de un estudio cualitativo, sectorial, exploratorio de casos múltiples. El estudio produjo un modelo de análisis asociando accionabilidad e integridad de forma única. Como contribución, se elaboró una propuesta de matriz de relación para verificar si las empresas poseen efectivamente un área de IC y no de espionaje, especulación o almacenamiento; en la matriz, los elementos constitutivos de los atributos de la Accionabilidad y la Integridad se miden y se clasifican. Entre las empresas encuestadas, sólo tres de ellas demostraron capacidad plena de construcción de un área de IC. La principal contribución de este trabajo fue guardar similitud con las herramientas estratégicas tradicionales y asociar dos concep tos esenciales a la verificación de la capacidad competitiva de la empresa.

Palabras clave: Inteligencia Competitiva. Procesable. Integridad.

\footnotetext{
${ }^{1}$ Doutor em Administração pela Universidade Federal de Minas Gerais - UFMG. Professor da Universidade FUMEC. Brasil. E-mail: reisnetomario@gmail.com

${ }^{2}$ Mestre em Engenharia de Produção pela Universidade Federal de Santa Catarina - UFSC. Professor da Universidade Federal Rural do Rio de Janeiro - UFRRJ. Brasil. E-mail: mldusi@gmail.com

${ }^{3}$ Mestre em Administração pelo Centro Universitário UNA. Brasil. E-mail: ricardoleopoldo@yahoo.com.br

4 Doutor em Administração pela Universidade Federal de Minas Gerais - UFMG. Professor do Mestrado em Administração do Centro Universitário UNA. Brasil. E-mail: luizrcmoura@gmail.com
} 


\section{INTRODUÇÃO}

Os cenários atuais, pelos quais passam as organizações, estão sujeitos a mudanças constantes, que as afetam direta e indiretamente, podendo sugerir alterações nos procedimentos operacionais e estratégicos, segundo Liu (2013) a competitividade das operações de fabricação em situações de negócios dinâmicos e complexos depende de estratégias com visão de futuro. As recessões econômicas que afetam as empresas, independentemente da localização, o aumento da concorrência e mudanças nas expectativas dos clientes, todos contribuem para as que as empresas sejam resilientes. Os desafios pelos quais as organizações passam ao longo de sua história são proporcionados por aspectos como ambiente econômico, político, tributário, concorrência, clientes, infraestrutura, etc. O sucesso ou fracasso é resultado direto da capacidade de se adaptar estrategicamente a essas variáveis; segundo Pereira e Hanashiro (2010), a gestão deve as segurar o cumprimento da missão, desta forma, o autor sugere que as empresas devam dar foco ao pensamento estratégico, devem começar por direcionamento geral que oriente as ações e os resultados esperados.

Nesse contexto, as organizações tendem a desenvolver modelos estratégicos que busquem a eficiência, como condição para se adaptar a este ambiente competitivo. Segundo Søderberg (2015), a estratégia não é algo que uma organização tem; é algo que seus membros fazem através de várias ações, interações e negociações com ambiente interno e como externo, sob essa ótica, uma alternativa de implementação estratégica é a Inteligência Competitiva (IC), cujo objetivo é promover ações que conduzam a empresa à conquista de vantagem mensurável e sustentável ante seus concorrentes (Barclay \& Kaye, 2000). Nesse cenário, a Inteligência Competitiva ganha importância e projeção, pois é capaz de produzir singularidade ao conhecimento extraído de informações (Fuld, 2007). Conforme Miller (2002), ao internalizar dados e notícias, analisá-los e correlacionálos à realidade da empresa, surge um conhecimento único, diferente daqueles disponíveis aos concorrentes.

A Inteligência Competitiva municia os gestores com informações capazes de aprimorar suas resoluções (Miller, 2002). Segundo Fleisher, Wright, e Trindade (2010), os tomadores de decisão equipados coma visão de IC melhoram o desempenho dos seus julgamentos. Os produtos também geram benefícios às demais atividades organizacionais: potencializam a competitividade da empresa, permitem a criação de vantagem competitiva e elevam a segurança na tomada de decisão, além de reduzir riscos operacionais (Degent, 1986; Marcial, Costa \& Curvello, 2002;
Gilad, 2011). Nesse processo de criação de conhecimentos exclusivos e construtivos, Fuld (2007) e Ramos e Moreti (2008) sugerem que esses sejam produzidos com clareza, velocidade e precisão. Tornálos acionáveis é uma realidade (Fleisher \& Bensoussan, 2003; Juhari \& Stephens, 2006).

A IC apoia as decisões nas empresas, ao construir conhecimentos acionáveis, lastreados em padrões e tendências, identificados na coleta e tratamento das informações e contextualizados a sua realidade singular (Clerc, 1997). Assim, segundo Fleisher e Bensoussan (2003), a Acionabilidade reflete a dimensão da Inteligência Competitiva que permite aos produtos e serviços desenvolvidos pela função serem acionados pelos tomadores de decisão e criarem efetivo valor ao negócio.

Todavia, de pouco adianta a Acionabilidade da IC, se a função não for contínua e sustentável. Devido a sua associação às atividades de espionagem, ela apresenta dificuldade de legitimar-se no setor privado (Sawka, 2000). Portanto, a Integridade - capacidade da IC de suportar as demandas de informações e de inferências de uma instituição de forma ética, transparente e em conformidade com as leis - que distingue a Inteligência de práticas duvidosas.

Portanto, a IC deve adotar práticas associadas à ética, à legalidade e à transparência para sobreviver e consolidar sua posição e sua efetividade no mundo de negócios (Gomes \& Braga, 2004; Crane, 2005). Afirmam Marcial, Costa e Curvelo (2002): "somente por meio de atitudes concretas é que a atividade de IC forjará uma identidade as sociada à ética e à transparência". A ausência desses valores torna o acesso às fontes de informação insustentável, assim como expõe a empresa a elevados riscos de imagem e de negócio.

Fleisher, Wright e Tindale (2007) afirmam que o tema está em expansão mediante a proliferação de programas de ensino da Inteligência e o aumento das publicações sobre o assunto. Além disso, são o sucesso e as contribuições únicas do campo que têm consolidado a IC como uma distinta disciplina da Administração (Juhari \& Stephens, 2006)

Esse estudo se justifica porque, para execução plena das atividades de IC nas organizações, nota-se que o campo de estudo ainda precis a de conhecimento próprio. As organizações necessitam melhorar o entendimento sobre como construir suas áreas de IC.

Este artigo trabalha com a premissa que as áreas de IC, necessitam da Integridade e da Acionabilidade, para identificar a aplicação adequada dos procedimentos de gestão da inteligência competitiva, possibilitando as organizações transitarem ou evitarem áreas similares, conforme quadro abaixo: 


\begin{tabular}{|c|c|}
\hline Espionagem & Inteligência Competitiva \\
\hline Especulação & Armazenamento \\
\hline
\end{tabular}

Quadro 1 - Síntese de análise áreas de IC e similares Fonte: Elaborado pelo autor

Ao garantir a Integridade e a Acionabilidade, a IC cria um ambiente favorável à ininterrupta criação de valor para o negócio. Nesse contexto, surge a seguinte questão: como se associam, Integridade e Acionabilidade, na utilização da Inteligência Competitiva? Dessa forma, o objetivo desse trabalho é propor uma matriz de relacionamento entre os conceitos de Acionabilidade e Integridade que permita verificar a capacidade da empresa na área de IC.

\section{ACIONABILIDADE}

A Acionabilidade é um conceito desenvolvido por Fleisher e Bensoussan (2003) que sugere que os produtos elaborados pela IC devem ser acionáveis pela organização, garantindo desta forma utilidade a eles. Para a devida aplicação da Acionabilidade, os autores, desenvolveram o sistema FAROUT (sigla, em inglês, composta pelas iniciais dos atributos Future Orientation, Accuracy, Resource Efficiency, Objectivity, Usefulness e Timeliness) que organiza as produções da IC segundo os seguintes atributos: visão orientada para o futuro, precisão, eficiência de recursos, objetividade, utilidade e oportunidade. $\mathrm{O}$ objetivo do sistema é sustentar a escolha das técnicas analíticas mais adequadas para cada necessidade de informação crítica da empresa (Fleisher \& Bensoussan, Strategic and Competitive Analaysis:Methods and Techniques for Analyzing Business Competition., 2003).

É importante salientar que a Inteligência Competitiva permite a reconstrução de dados desvinculados em informações acionáveis (Tarapanoff, 2001). Ela deve orientar seus usuários sobre as ações a serem tomadas e ainda prover indicadores sobre estas decisões recomendadas (Cleland \& King, 1975). Se ela não produz conhecimentos que possibilitem a ação oportuna, sua utilidade se limita em alto grau. Portanto, a Acionabilidade é o que permite que a Inteligência Competitiva seja efetivamente utilizada pelos tomadores de decisão. Para desenvolver tal característica, é preciso que os produtos de IC atendam a certos fatores determinantes de seu sucesso. Umdos modelos que podem avaliar esta característica é o sistema FAROUT.

Segundo Fleisher e Bensoussan (2003), o sistema FAROUT baseia-se na premissa de que, para transformar a análise em Inteligência Acionável e útil aos tomadores de decisão, é preciso que os produtos tenham os seguintes atributos: visão orientada para o futuro, precisão, eficiência de recursos, objetividade, utilidade e oportunidade. $\mathrm{O}$ objetivo do sistema é sustentar a escolha das técnicas analíticas mais adequadas para cada necessidade da informação crítica da empresa (Fleisher \& Bensoussan, Strategic and Competitive Analaysis:Methods and Techniques for Analyzing Business Competition., 2003).

A visão orientada para o futuro ensina que o passado pode ser umindicador impreciso e perigoso na construção de inferências, ou seja, a IC deve ser prospectiva: analis ar ampla e profundamente o futuro indeterminado e incerto - e se dispor a correr riscos por ser preditiva e inventiva (Fleisher \& Bensoussan, Strategic and Competitive Analaysis:Methods and Techniques for Analyzing Business Competition., 2003).

Fleisher e Bensoussan (2003) explicam que a precisão deve desenvolver análises que visem elevado grau de assertividade. Para Ramos e Moreti (2008), garantir a veracidade e qualidade das informações impacta diretamente na eficácia do processo de IC. Níveis elevados de precisão são difíceis de alcançar, quando os dados vêm de apenas uma fonte; as informações não são validadas; os dados precisam ser convertidos de um modo pelo qual não foram originalmente concebidos; e as informações partem de fontes repletas de viés (Fleisher \& Bensoussan, Strategic and Competitive Analaysis:Methods and Techniques for Analyzing Business Competition., 2003).

A oportunidade refere-se ao risco existente no tempo gasto pelo o analista para realização de uma demanda (Fleisher \& Bensoussan, Strategic and Competitive Analaysis:Methods and Techniques for Analyzing Business Competition., 2003) . Fleisher e Bensoussan (2003) explicam que grande parte dos dados tem uma vida útil limitada, especialmente quando a tomada de decisão ocorre em ambientes dinâmicos, hipercompetitivos, e turbulentos. "Esperar é dar aos outros a chance de realizar a mesma oportunidade" (Fuld, 2007). Fleisher e Bensoussan ( 2003) concluem que a análise valiosa é aquela que dá o prazo suficiente para a empresa implementar o curso de ação recomendado pela análise.

Outro fator é a eficiência dos recursos. Segundo Fleisher e Bensoussan (2003) para que a análise seja feita de forma eficiente, os dados precisam vir de fontes mais baratas do que o valor necessário para produzir seus resultados e não devem demorar muito tempo para serem coletados, a fim de que não se tornem obsoletos. Ramos e Moreti (2008) sugerem a adoção de três ações cujos impactos afetam diretamente a eficácia do processo de IC: utilizar redes 
humanas, acessar intensamente fontes primárias e adotar soluções de Tecnologia da Informação para aproximar as pessoas e as unidades de negócio.

A objetividade refere-se à presença de vieses no perfil dos analistas ou das organizações (Fleisher \& Bensoussan, Strategic and Competitive Analaysis:Methods and Techniques for Analyzing Business Competition., 2003). Muitas análises são constantemente influenciadas por vieses cognitivos ou sociais, desde a construção das premissas até o pensamento predominante de um grupo na abordagem dos riscos ou incertezas. Para minimizar a natureza destrutiva dos vieses, (Fleisher \& Bensoussan, Strategic and Competitive Analaysis:Methods and Techniques for Analyzing Business Competition., 2003) propõem analisar os dados ou informações sob uma abordagem racional e sistemática.

Sobre a utilidade, Fleisher e Bensoussan (2003) ensinam que os produtos de IC considerados valiosos são aqueles que atendem as necessidades de inteligência do usuário no contexto do processo decisório. A análise ou inferência efetiva deve ser adequada às responsabilidades do gestor, à realidade da empresa e ao estilo de comunicação (Fleisher \& Bensoussan, Strategic and Competitive Analaysis:Methods and Techniques for Analyzing Business Competition., 2003). Portanto, é preciso que o analista desenvolva produtos "essenciais de saber" e não os "interessantes de saber" para que atendam ou superem às necessidades do usuário-final (Fleisher \& Bensoussan, Strategic and Competitive Analaysis:Methods and Techniques for Analyzing Business Competition., 2003).

Para a aplicação do sistema FAROUT, cada atributo é avaliado mediante uma escala que varia de 1 a 5 , onde 1 indica baixo nível de orientação e 5 quando é altamente focado.

A prerrogativa de aplicar o sistema FAROUT para avaliar a Acionabilidade da IC na perspectiva de seus usuários e desvendar a percepção de valor das atividades abre a possibilidade de encontrar um mecanismo aderente, capaz de examinar e estimular a produção de Inteligência, cada vez mais útil e acionável para as empresas. Todavia, não basta a IC ser acionável, ela precisa ser íntegra para afastar definitivamente ações de práticas não recomendadas no ambiente corporativo.

$\mathrm{O}$ conceito de Acionabilidade contribuiu para a construção da IC, mas não é o único pilar; outro aspecto relevante é a Integridade, cujo objetivo é de oferecer consistência ética e legal aos produtos de Inteligência Competitiva.

\section{INTEGRIDADE}

A Integridade é um conceito sugerido por Marcial, Costa e Curvelo (2002), que propõem o uso de práticas legais e éticas para buscar informações que irão sustentar os produtos desenvolvidos pela IC. Importante ressaltar, segundo a Associação Brasileira dos Analistas de Inteligência Competitiva (Associação Brasileira dos Analistas de Inteligência Competitiva, 2011), é tênue a linha divisória entre IC e espionagem. Ensina Rodrigues, Miranda e Crespo (2010) "que há a necessidade de que os profissionais mantenham atitudes éticas, postando-se ao lado da pesquisa de informações legítima e legal, alijando a espionagem industrial". Assim, o que distingue a função de IC da espionagem são as práticas legais e éticas de buscar informações (Marcial, Costa, \& Curvelo, Lícito versus Ético: Como as Ferramentas da Inteligência Competitiva Podem para a Boa Imagem Corporativa, 2002).

Para afastar-se da influência de especulações e da espionagem, atributo tão imprescindível que à IC que a Society of Competitive Intelligence Professionals (SCIP) criou diretrizes, em seu código de ética, para nortear a ação dos profissionais de inteligência e distanciá-la da espionagem industrial (ou econômica) e dos métodos ilegais de coleta de informações (SCIP, 2012). Ela consiste na capacidade da inteligência de apoiar plenamente - de forma ética, transparente e em conformidade com as leis - as demandas de informações da empresa. Ela torna o ciclo de IC sustentável e o distancia de práticas não recomendáveis.

Kalb (2000) define a conduta antiética como "aquela que não se enquadra nos padrões da própria profissão, dos colegas, do empregador ou de outro grupo regulamentador". A ética pode ser definida como o grupo de valores, princípios e virtudes que conduzem as relações humanas (Marcial, Costa, \& Curvelo, Lícito versus Ético: Como as Ferramentas da Inteligência Competitiva Podem para a Boa Imagem Corporativa, 2002). Ela e a legalidade devem permear sempre o processo de coleta de dados (Cleland \& King, 1975; Clerc, 1997; Gomes \& Braga, 2004). Para Kalb (2000), a ilegalidade reflete "a conduta que configura uma violação da lei”. Não respeitar tais limites significa infringir as leis que regem as relações de mercado e is so pode desencadear consequências civis ou criminais para os profissionais e expor a empresa a riscos (Kalb, 2000).

Crane (2005) considera a busca de informações de caráter particular ou confidencial como um dos principais problemas à ética e a legalidade. Clerc (1997) completa que a Inteligência deve explorar somente as fontes publicáveis. Com o intuito de evitar problemas sobre o uso ético e legal das metodologias de IC, Gomes e Braga (2004) sugerem às organizações a criação de um código de ética. De acordo com Marcial, Costa e Curvelo (2002), "código de ética para a Inteligência Competitiva tem como objetivo nortear o trabalho do profissional de IC, principalmente nas etapas de coleta de dados e pedaços de informação, fase em que há dúvidas quanto ao que é certo ou errado". 
Sobre a Transparência Fuld (2007) indica a falta dela como o problema mais significante ao avaliar a preparação das empresas para a competição, ou seja, quanto mais visível a área de IC for e quanto mais interação ela estabelecer com as demais áreas, melhor (Sawka, 2000). Assim, o trabalho em rede se torna uma de suas principais ferramentas (Ramos \& Moreti, Inteligência Competitiva: Aspectos Críticos na Empresa Brasileira, 2008). Ela não só ganha em interação com as demais áreas como também consolida o processo de legitimação da função de IC dentro das organizações (Sawka, 2000).

Portanto, tornou-se primordial defender a Integridade em todas as etapas do seu ciclo, pautadas sempre na Ética, na Legalidade e na Transparência. Somente assim, será possível criar conhecimento acionável, de forma íntegra e sustentável.

Os pilares Acionabilidade e Integridade formam o arcabouço de sustentação para construção de modelos de Inteligência Competitiva eficientes, transparentes e éticos em relação ao mercado. Estes constructos oferecem à IC a oportunidade de se diferenciar dos conceitos de espionagem, armazenagem e especulação apresentados no tópico seguinte.

\section{INTELIGÊNCIA COMPETITVA ESTRATÉGIA} $\mathbf{E}$

Segundo Miller (2002), a IC refere-se ao processo de monitoramento ambiental do mercado, focado nos principais concorrentes e suas possíveis ações. Adicionalmente, Herring (1996) afirma que: "Inteligência é o conhecimento do ambiente competitivo da organização e de seu macroambiente, aplicado a processos de tomada de decisão, nos níveis estratégico e tático". Segundo Yap e Rashid (2011) a IC é a busca por informações distribuídas de forma desordenada nas organizações e a transformação em conhecimento acionável para decisões estratégicas. A Inteligência Competitiva ainda é um conceito em transformação, não há um significado geral e abrangente (Combs \& Moorhead, 1992; Fleisher \&Bensoussan, 2007). Ela ainda é o processo de transformação de informações desagregadas em conhecimento sensível sobre a movimentação, as capacidades, os propósitos e o desempenho dos concorrentes (Sammon, Kurland \& Splitalnic, 1984; Combs \& Moorhead, 1992).

Assim com a IC o processo formação de estratégia integra os níveis hierárquicos num processo de troca de conhecimentos, geração de ideias, trabalho em equipe, integrando análise, formulação e experiências práticas para que este processo possa gerar aprendizagens e, as aprendizagens gerarem inovações de forma contínua e progressiva (Gonzalez \& Campos, 2015)

Os conceitos de IC e estratégica transitam entre linhas tênues de distinção entre os mesmos, possivelmente com mais pontos de intercessão do que diferenciação. Do ponto de vista histórico, a Inteligência Competitiva destacou-se como opção estratégica organizacional a partir da década de 1980 (Fleisher \& Bensoussan, 2003; Gilad, 2011). Porém, vários especialistas atribuem sua origem no ambiente de negócio às décadas de 1960 e 1970 (Martinet \& Marti, 1995; Prescott, 1999; Toledo \& Toledo, 2007). Clerc (1997) explica que, neste período, foram criados os primeiros departamentos de Inteligência em organizações privadas. A atividade surgiu sob forte influência da espionagem governamental e da inteligência militar (Kelley, 1968; Gomes \& Braga, 2004).

Um aspecto relevante para a construção da IC é a coleta de dados, para Prescott (1999), a busca de informações - no princípio, informal e tática - foi a primeira atividade de IC. Logo, a busca por conhecer as inovações e novidades dos concorrentes tornou-se uma atividade comum entre as grandes empresas (Degent, 1986). O uso e a relevância da prática crescem à medida que o impacto potencial das informações acionáveis nos fatores cruciais do negócio é reconhecido (Juhari \& Stephens, 2006).

Para Juhari e Stephens (2006), a explosão de novas Tecnologias de Informação e de Comunicação (TICs) provavelmente atribuíram a noção de IC como algo novo e até revolucionário. Diante de tamanha evolução, a Inteligência Competitiva migrou de uma atividade informal e tática para um processo formal e estratégico (Prescott, 1999).

Devido à relação intensa com as demais atividades da empresa, a IC passa a ser valorizada como uma função crítica na execução de melhores decisões (Zangoueinezhad \& Moshabaki, 2008). Assim, ela passa a ser entendida como uminstrumento interno de execução do planejamento e da estratégia corporativa (Fernandez \& Lana, 2008). Ela também é definida como fonte de informação para suportar o processo decisório (Tarapanoff, 2001). Por sua vez, Combs e Moorhead (1992) afirmam que "a chave para o sucesso da Inteligência Competitiva é fornecer ao gestor, as informações que ele ou ela realmente necessitam". Para Fuld (2007), "Inteligência é tomar decisões críticas com conhecimento imperfeito, mas razoável, e com um grau de risco."

Gilad (2004) defende que o risco é o ponto central da Inteligência Competitiva, Lesca, Freitas, e Cunha (1996) informam que a IC busca reduzir os riscos ligados à incerteza, por meio da escuta antecipativa dos sinais fracos do ambiente socioeconômico. Ela é "um processo [...] que visa descobrir as forças que regem os negócios, reduzir o risco e conduzir o tomador de decisão a agir proativamente, bem como para proteger o conhecimento sensível produzido" (Marcial, Costa, \& Curvelo, Lícito versus Ético: Como as Ferramentas da Inteligência Competitiva Podem para a Boa Imagem Corporativa, 2002). Fernandez e Lana (2008) reforçam 
que a IC é um processo de vigília constante que identifica oportunidades de negócio e os riscos.

Hodges (2005) adiciona que a IC é o processo de coleta, organização e disseminação das informações geradas a partir da identificação e da avaliação sistemática dos objetivos, das forças, das fraquezas e das linhas de produtos dos rivais. Fuld (2007) ainda completa que a verdadeira Inteligência Competitiva reflete a habilidade para antecipar o próximo movimento dos concorrentes. Fleisher e Bensoussan (2003) finalizam que ela "é um processo, ético e legal, composto de variáveis que, finalmente, podem fazer de uma organização o jogador dominante ou quebrá-la". Por isso, Fleisher, Wright, e Tindale (2007) concluem que "o campo de IC e a sua gestão sofrem da variedade semântica e da predominância da ambiguidade que permanece sem solução após várias décadas de trabalho de investigação". Portanto, embora existam diversas tentativas de dar significado à Inteligência Competitiva, o conceito ainda pode ser demasiado vago (Gilad, 2004).

Segundo Pereira, Mafra, e Ricardo (2016), a IC pode aumentar a capacidade competitiva das empresas, pois tornam inteligente o uso da informação, contribuindo com a redução de incertezas nas decisões estratégicas. A IC é desenvolvida com a definição dos objetivos e em cronologia segundo seus ciclos operacionais, conforme descrito nas etapas subsequentes.

\section{CICLO DA INTELIGÊNCIA COMPETITIVA}

O ciclo de IC é um dos modelos mentais básicos para a atividade (Ganesh, Miree, \& Prescott, 2003). A definição clássica do ciclo de IC enumera quatro etapas sequenciais e consecutivas: a identificação das necessidades de Inteligência, a coleta de informações, a análise dos dados e a disseminação dos produtos para os usuários (Miller, 2002). Dentre as variações deste modelo, Gomes e Braga (2004) incluem uma fase de avaliação após a difusão dos produtos de Inteligência aos decisores. Gilad (2004) define as cinco etapas de IC como coleta, avaliação, armazenamento, análise e disseminação. Bouthillier e Shearer (2003) detalham o process o nas seguintes etapas: identificação de necessidades, aquisição, organização, armazenamento e recuperação, análise, produção de relatórios e divulgação. Comai e Millán (2006) incluem ainda o processo de avaliação - feedback - como uma etapa-chave da atividade de IC que interage diretamente com todas as demais fases.

Ao considerar a definição clás sica composta por quatro etapas distintas e consecutivas, torna-se necessário entender as particularidades de cada fase. A identificação de necessidades seleciona as principais variáveis que demandam monitoramento e análise dos profissionais de Inteligência (Miller, 2002). Explicam Gomes e Braga (2004), "a partir dessa identificação é possível determinar as informações que deverão ser coletadas e analisadas sob a ótica da estratégia da empresa, de modo a auxiliar a tomada de decisão".

A coleta de informações consiste na obtenção de dados junto às fontes de informação, conforme as demandas e os processos definidos, transformando dados brutos em informações viáveis, com o cuidado de balancear o tempo e recursos gastos na obtenção de informações externas impressas e de fontes individuais internas e externas (Degent, 1986; Fuld 1995; Hohhof, 2002).

$\mathrm{Na}$ análise de dados é onde se pretende converter e correlacionar informações aparentemente distintas e desconexas em conhecimentos significativos e úteis aos tomadores de decisão (Combs \& Moorhead, 1992; Fuld, 1995; Clerc, 1997). Afirmam Combs e Moorhead (1992): "A informação não tem vida, a menos que ela signifique alguma coisa". Assim, os profissionais de IC procuram interpretar os dados, os padrões e as tendências existentes até se obterem insights exclusivos e relações ainda não observadas entre os dados (Miller, 2002).

$\mathrm{Na}$ etapa de disseminação, os produtos de Inteligência Competitiva são disponibilizados aos usuários. Seu formato e sua utilidade variam conforme as necessidades dos usuários e o grau de informação e análise contido em cada material (Ramos \& Moreti, Inteligência Competitiva: Aspectos Críticos na Empresa Brasileira, 2008). Para Combs e Moorhead (1992), o timing é fundamental. "Não importa quão boa seja a análise [...], salvo se o assunto é comunicado àqueles que precisam saber, a tarefa é inútil" (Combs \& Moorhead, 1992). Degent (1986) recomenda três diretrizes básicas na disseminação: a canalização das informações necessárias para cada tomador de decisão; a racionalização das informações (eliminação de tudo que não for relevante); e a coleta e transmissão das informações em momento oportuno, de acordo comsua urgência.

Assim, quando as quatro etapas do ciclo ocorrem de forma adequada, é que os produtos de Inteligência alcançarão alto valor agregado para seus usuários e estarão aptos a serem desenvolvidos conforme o modelo apresentado nos tópicos seguintes.

\section{METODOLOGIA}

Esse artigo foi estruturado por uma pesquisa qualitativa descritiva que, segundo Malhorta (2011), visa interpretar as funções ou características do objeto estudado. Neste estudo foi usado o corte transversal único, no qual se coletam os dados da amostra uma única vez. O processo permite uma compreensão inicial do assunto e proporciona insights e a contextualização do problema (Malhorta, 2011).

$\mathrm{O}$ artigo trabalha o tema através da modelagem que é uma tentativa de reduzir a complexidade da realidade em um estudo, de modo a torná-la tangível à 
racionalidade humana (Lapponi, 2003). O modelo proposto tem o intuito de explicar a associação das dimensões - Acionabilidade e Integridade - para geração plena e efetiva da atividade de IC nas organizações.

As dimensões acionabilidade e integridade são compostas por atributos causais. O somatório da contribuição individual de cada um destes fatores cria a percepção de Acionabilidade (visão de futuro, objetividade, eficiência dos recursos, utilidade, precisão e oportunidade) e de Integridade (ética, a legalidade e a transparência) da IC (Fleisher \& Bensoussan, Strategic and Competitive Analaysis:Methods and Techniques for Analyzing Business Competition., 2003). Os resultados da associação das dimensões são repres entados em quatro setores que refletem a intensidade das dimensões, cuja variação oscila de 'Baixa' a 'Alta'. Cada setor foi nomeado de acordo com a associação da intensidade das dimensões em estudo: Especulação (baixa integridade, baixa acionabilidade), Armazenagem (alta integridade, baixa acionabilidade), Espionagem (baixa integridade, alta acionabilidade) e Inteligência (alta integridade, alta acionabilidade) (Marcial, Costa, \& Curvelo, Lícito versus Ético: Como as Ferramentas da Inteligência Competitiva Podem para a Boa Imagem Corporativa, 2002).

O setor Especulação é caracterizado por resultados baixos nas duas dimensões; informações não são construídas da forma recomendada e não são transformadas em ações. No caso de alta Acionabilidade e baixa Integridade, setor Espionagem, a atividade possui orientação para a ação, mas durante a construção do conhecimento não existe tanto cuidado com a ética, a legalidade e a trans parência. Os produtos são capazes de influenciar as decisões, porém seu processo não é sustentável e pode implicar riscos de imagem e negócio. No setor Armazenagem, quando a Acionabilidade é baixa e a Integridade alta, as empresas possuem processos estruturados (da coleta à disseminação), mas eles não são executáveis. A atividade assemelha-se a uma biblioteca: ocupa-se mais em armazenar os conhecimentos do que em torná-los efetivamente acionáveis. Quando os valores da Acionabilidade e da Integridade são altos, setor Inteligência, as organizações criam produtos de forma ética e sustentável, e ainda os fazem acionáveis, o que gera elevado valor ao negócio. A empresa antecipa seus movimentos, acompanha seu mercado e age quando necessário. Assim, ela cria processos sustentáveis e transparentes que não implicam em riscos legais e de negócio.

Proposto o modelo, ele serviu de base conceitual para as sociação das variáveis pesquisadas na efetiva criação de valor nos produtos de IC a partir da percepção de seus usuários .

A aplicação do modelo segue o seguinte comportamento para as médias alcançadas pelas organizações, segundo a metodologia de pesquisa:

\begin{tabular}{|c|c|c|c|c|}
\hline & Especulação & Armazenamento & Espionagem & IC \\
\hline Acionabilidade & Baixa & Baixa & Alta & Alta \\
\hline Integridade & Baixa & Alta & Baixa & Alta \\
\hline
\end{tabular}

Quadro 2 - Síntese de análise do modelo de as sociação entre Acionabilidade x Integridade Fonte: Elaborado pelo autor.

O instrumento de coleta de dados foi constituído por um questionário estruturado que se encontra transcrito abaixo Para Malhorta (2011), a construção do questionário consiste na série de perguntas que um entrevistado deve responder, por escrito ou oralmente. Ele cumpre três funções essenciais: traduzir a informação desejada em um conjunto de questões específicas; estimular o entrevistado a se deixar envolver pelo assunto; e minimizar o erro na resposta (Malhorta, 2011).

\section{Questionário de Pesquisa:}

\section{PARTE 1 - PERCEPÇÃO DOS ATRIBUTOS DE ACIONABILIDADE}

1. Roteiro de acesso exclusivo do pesquisador. Leia cada uma das afirmações a seguir e responda de acordo com a escala. Considere 1 para NUNCA se aplica e 5 para SEMPRE se aplica. 


\begin{tabular}{|c|c|c|c|c|c|}
\hline \multirow{2}{*}{$\begin{array}{l}\text { Os produtos de IC oferecidos em sua empresa antecipam } \\
\text { o futuro? }\end{array}$} & 1 & 2 & 3 & 4 & 5 \\
\hline & & & & & \\
\hline \multicolumn{6}{|l|}{$\begin{array}{l}\text { Os produtos de IC oferecidos em sua empresa identificam } \\
\text { tendências futuras? }\end{array}$} \\
\hline \multicolumn{6}{|l|}{$\begin{array}{l}\text { As análises existentes nos produtos de IC são construídas } \\
\text { com base em informações históricas? }\end{array}$} \\
\hline \multicolumn{6}{|l|}{ Os produtos de IC orientam as ações futuras da empresa? } \\
\hline \multicolumn{6}{|l|}{$\begin{array}{l}\text { A unidade de IC utiliza fontes primárias para construção } \\
\text { das informações acionáveis? }\end{array}$} \\
\hline \multicolumn{6}{|l|}{$\begin{array}{l}\text { Os dados e informações utilizados nos produtos de IC são } \\
\text { validados? }\end{array}$} \\
\hline \multicolumn{6}{|l|}{ O conteúdo dos produtos de IC transmite precisão? } \\
\hline \multicolumn{6}{|l|}{$\begin{array}{l}\text { As fontes de dados apresentadas nos produtos de IC } \\
\text { transmitem confiabilidade? }\end{array}$} \\
\hline \multicolumn{6}{|l|}{$\begin{array}{l}\text { A unidade de IC possui sistema ou ferramenta de suporte } \\
\text { ao processo de Inteligência na organização? }\end{array}$} \\
\hline \multicolumn{6}{|l|}{$\begin{array}{l}\text { Os recursos disponíveis para a atividade de IC são } \\
\text { suficientes para realização plena da função? }\end{array}$} \\
\hline \multicolumn{6}{|l|}{$\begin{array}{l}\text { As redes internas e externas são acionadas pela equipe de } \\
\text { IC? }\end{array}$} \\
\hline \multicolumn{6}{|l|}{$\begin{array}{l}\text { Como é o uso das fontes primárias e secundárias na } \\
\text { elaboração dos produtos de IC? }\end{array}$} \\
\hline \multicolumn{6}{|l|}{$\begin{array}{l}\text { Os produtos de IC apresentam os vieses dos analistas de } \\
\text { Inteligência? }\end{array}$} \\
\hline \multicolumn{6}{|l|}{$\begin{array}{l}\text { A cultura da organização interfere nas análises e } \\
\text { conteúdos dos produtos de IC? }\end{array}$} \\
\hline \multicolumn{6}{|l|}{$\begin{array}{l}\text { Os produtos de IC apresentam racionalidade e sistemática } \\
\text { em seu conteúdo? }\end{array}$} \\
\hline \multicolumn{6}{|l|}{ As análises e recomendações de IC são imparciais? } \\
\hline \multicolumn{6}{|l|}{$\begin{array}{l}\text { Os produtos de IC são utilizados para a tomada de } \\
\text { decisão? }\end{array}$} \\
\hline \multicolumn{6}{|l|}{$\begin{array}{l}\begin{array}{l}\text { Os produtos de IC são aderentes à realidade da } \\
\text { organização? }\end{array} \\
\end{array}$} \\
\hline \multicolumn{6}{|l|}{$\begin{array}{l}\text { As análises e recomendações resultam em ações da } \\
\text { empresa? }\end{array}$} \\
\hline \multicolumn{6}{|l|}{$\begin{array}{l}\text { O entendimento do conteúdo dos produtos de IC é de } \\
\text { fácil entendimento? }\end{array}$} \\
\hline \multicolumn{6}{|l|}{$\begin{array}{l}\text { Os produtos de IC são disponibilizados em tempo hábil } \\
\text { para a tomada de decisão? }\end{array}$} \\
\hline \multicolumn{6}{|l|}{$\begin{array}{l}\text { As informações de IC fornecem tempo suficiente para } \\
\text { implantar o curso de ação recomendado? }\end{array}$} \\
\hline \multicolumn{6}{|l|}{$\begin{array}{l}\text { Os produtos de IC são entregues dentro dos prazos } \\
\text { estipulados? }\end{array}$} \\
\hline As informações de IC são as mais atuais possíveis? & & & & & \\
\hline
\end{tabular}




\begin{tabular}{|c|c|c|c|c|c|}
\hline & 1 & 2 & 3 & 4 & 5 \\
\hline $\begin{array}{l}\text { A empresa possui regras claras sobre a conduta ética } \\
\text { aceita pela empresa? }\end{array}$ & & & & & \\
\hline $\begin{array}{l}\text { A empresa se preocupa com a conduta dos seus } \\
\text { profissionais no exercício de suas funções? }\end{array}$ & & & & & \\
\hline $\begin{array}{l}\text { A empresa se preocupa com os riscos de negócio e } \\
\text { imagem gerados por condutas antiéticas de seus } \\
\text { profissionais? }\end{array}$ & & & & & \\
\hline $\begin{array}{l}\text { Como é o nível de conhecimento da empresa sobre a } \\
\text { legis lação que rege o uso das informações no } \\
\text { mercado? }\end{array}$ & & & & & \\
\hline $\begin{array}{l}\text { A empresa dissemina aos seus profissionais os } \\
\text { conhecimentos sobre a legis lação acerca do uso } \\
\text { permitido das informações de mercado? }\end{array}$ & & & & & \\
\hline $\begin{array}{l}\text { A empresa possui algum suporte jurídico para apoio às } \\
\text { dúvidas legais na coleta e uso das } \\
\text { informações de mercado? }\end{array}$ & & & & & \\
\hline $\begin{array}{l}\text { Os produtos de IC, caso acessados por competidores, } \\
\text { podem gerar riscos e processos judiciais junto } \\
\text { ao mercado? }\end{array}$ & & & & & \\
\hline $\begin{array}{l}\text { Os profissionais de IC estão acessíveis aos funcionários } \\
\text { dos demais setores da empresa? }\end{array}$ & & & & & \\
\hline $\begin{array}{l}\text { A função da unidade de IC é comunicado para os demais } \\
\text { setores da empresa? }\end{array}$ & & & & & \\
\hline $\begin{array}{l}\text { Os produtos de IC são construídos coletivamente com a } \\
\text { ajuda dos demais setores da empresa? }\end{array}$ & & & & & \\
\hline Os produtos de IC refletem os objetivos da unidade? & & & & & \\
\hline
\end{tabular}

A unidade de análise foi constituída de organizações com atividade econômica no Estado de Minas Gerais, com a função de Inteligência Competitiva em sua estrutura funcional. Apesar das limitações da amostragem não-probabilística, que impediu fazer inferências à população, Triviños (1987) defende o procedimento porque nele o pesquisador escolhe intencionalmente os entrevistados e para isso considera uma série de condições tais como: os sujeitos essenciais para esclarecer o assunto; a facilidade para encontrar as pessoas e o tempo dos pesquisados para a entrevista. Optou-se por empregar a amostragem por conveniência e por julgamento. Malhorta (2011) explica que o pesquisador "exercendo seu julgamento ou aplicando sua experiência, escolhe os elementos a serem incluídos na amostra, pois os consideram representativos da população de interesse, ou apropriados por algum outro motivo"

Trata-se de um estudo qualitativo, setorial, exploratório e de casos múltiplos, a comparação de dados é elaborada por um sistema racional. Foram escolhidas propositalmente empresas com características que pudessem ser enquadradas nos diversos quadrantes propostos por este artigo

Para Malhotra (2001), ainda existem duas classificações nas pesquisas descritivas: a transversal e a longitudinal. Enquanto os estudos longitudinais envolvem uma amostra fixa de elementos da população que é medida repetidamente, o corte transversal emprega a coleta de informações de elementos da população uma única vez. As pesquisas transversais são tipificadas em corte único ou múltiplo (Malhotra, 2001). O corte transversal múltiplo envolve duas ou mais amostras de entrevistados. Por sua vez, o corte transversal único extraí da população uma única amostra de entrevistados.

Nesta pesquisa empregou-se o corte transversal único, uma vez que foi extraída somente uma amostra das organizações com a função de Inteligência instituída, não sendo objetivo do estudo, analisar as mudanças ao longo do tempo nas características dos indivíduos. Portanto, os dados foram coletados de uma amostra, por conveniência, da população de empresas com função de IC constituídas, somente uma vez.

Os dados foram coletados por meio de oito entrevistas presenciais, uma por empresa, com um usuário de produtos de IC. Todos os entrevistados ocupavam cargos decisórios (assessor de diretoria, gerentes de departamento, diretores executivos e vicepresidente). Para Cruz e Ribeiro (2003), a técnica consiste numa "conversa orientada para um fim específico, ou seja, recolher dados e informações".

Cada um dos atributos que compõem as dimensões Acionabilidade e Integridade (Fleisher \& Bensoussan, 2003; Marcial, Costa \& Curvello, 2002) tiveram quatro questões para avaliá-los. Foi utilizada uma escala de cinco pontos para medir a intensidade de cada variável pesquisada. Os itens que possuem baixa 
Acionabilidade ou Integridade são classificados com o valor 1 e os itens que possuem alta Acionabilidade ou Integridade receberam o valor 5. Esses itens são avaliados separadamente. Como todo método científico, o procedimento escolhido possui vantagens e desvantagens. Malhorta (2011) evidencia a capacidade de aprofundamento como um dos principais diferenciais desta modalidade. Outra é a facilidade de atribuição das respostas a cada entrevistado. Quanto às desvantagens destacam-se: os custos e a potencial dificuldade de analisar e interpretar os dados obtidos (Malhorta, 2011).
Quanto à amostra, devido à confidencialidade dos dados, as instituições pesquisadas foram nominadas em empresas A, B, C, D, E, F, G e H. Quanto às caraterísticas da amostra, foram escolhidas por conveniência da pesquisa. Elas integram os seguintes setores: Administração Pública, Apoio ao Desenvolvimento Econômico, Comércio Atacadista, Instituições Financeiras, Órgãos e Associações de Classe e Petróleo e Gás. O detalhamento sobre a estrutura de IC em cada uma das empresas pode ser verificado no Quadro2.

\begin{tabular}{|c|c|c|c|c|}
\hline Empresa & $\begin{array}{l}\text { Equipe } \\
\text { de IC }\end{array}$ & $\begin{array}{l}\text { Estrutura no } \\
\text { Organograma }\end{array}$ & Público-Alvo & Demais Observações \\
\hline A & 10 a 15 & $\begin{array}{c}\text { Unidade } \\
\text { independente }\end{array}$ & $\begin{array}{c}\text { Diretores, Gerentes e } \\
\text { Analistas de atendimento }\end{array}$ & $\begin{array}{l}\text { Realiza atividades ligadas à } \\
\text { Gestão do Conhecimento }\end{array}$ \\
\hline B & 2 a 5 & $\begin{array}{c}\text { Unidade } \\
\text { independente }\end{array}$ & $\begin{array}{l}\text { Diretores e Profissionais } \\
\text { das unidades de mercado }\end{array}$ & $\begin{array}{l}\text { O foco são estudos setoriais e } \\
\text { análises econômicas }\end{array}$ \\
\hline $\mathrm{C}$ & 1 & $\begin{array}{l}\text { Unidade } \\
\text { mercadológica }\end{array}$ & Diretores e Gerentes & $\begin{array}{c}\text { Uso constante de outras } \\
\text { unidades, além de fornecedores } \\
\text { e clientes. }\end{array}$ \\
\hline $\mathrm{D}$ & 2 a 5 & $\begin{array}{l}\text { Unidade } \\
\text { independente }\end{array}$ & $\begin{array}{c}\text { Diretor, Gerentes e } \\
\text { demandas pontuais de } \\
\text { unidades internas }\end{array}$ & $\begin{array}{l}\text { O foco é a análise do ambiente } \\
\text { de negócio e o resultado dos } \\
\text { produtos }\end{array}$ \\
\hline $\mathrm{E}$ & 2 a 5 & $\begin{array}{c}\text { Unidade } \\
\text { independente }\end{array}$ & Diretores e Gerentes & $\begin{array}{l}\text { Parte dos produtos é orientada } \\
\text { ao mercado }\end{array}$ \\
\hline $\mathrm{F}$ & 2 a 5 & $\begin{array}{l}\text { Unidade } \\
\text { comercial }\end{array}$ & $\begin{array}{c}\text { Diretores, Gerentes e } \\
\text { demais Profissionais } \\
\text { internos } \\
\end{array}$ & $\begin{array}{l}\text { Parte dos produtos é orientada } \\
\text { ao mercado }\end{array}$ \\
\hline G & 2 a 5 & Diversas unidades & $\begin{array}{c}\text { Diretores, Gerentes e } \\
\text { Associados }\end{array}$ & $\begin{array}{c}\text { Atua como força-tarefa e } \\
\text { envolve vários departamentos da } \\
\text { empresa }\end{array}$ \\
\hline $\mathrm{H}$ & 2 a 5 & $\begin{array}{c}\text { Unidade } \\
\text { mercadológica }\end{array}$ & Diretoria e Gerentes & $\begin{array}{c}\text { Função de IC está nascente e em } \\
\text { recente estruturação }\end{array}$ \\
\hline
\end{tabular}

Quadro 3 - Estrutura de Inteligência Competitiva nas empresas pesquisadas Fonte: Elaborado pelo autor.

\section{APRESENTAÇÃO E ANÁLISE DOS RESULTADOS}

A presente pesquisa analisou a percepção dos usuários sobre o uso da IC, a Acionabilidade e a Integridade. Cada bloco de informação foi analisado separadamente, com o intuito de que fosse entendida a especificidade do fenômeno em cada um dos atributos estudados.

\subsection{Acionabilaide}

Visão orientada para o futuro - As organizações devem estar dispostas a correr riscos buscando se antecipar ao indeterminado pelo futuro (Fleisher \& Bensoussan, Strategic and Competitive Analaysis:Methods and Techniques for Analyzing Business Competition., 2003), por esta perspectiva apenas as empresas A e C tiveram avaliação alta neste atributo (acima de 3). As demais apresentaram valores baixos (1 e 2), fato que aponta uma insuficiência de foco no futuro dos produtos de IC. Nas entrevistas, constatou-se o foco predominante em monitorar o cenário presente. Na percepção dos entrevistados, apenas as empresas $\mathrm{A}$ e $\mathrm{C}$ incluem constantemente uma visão de médio e longo prazo em seus produtos. As outras organizações concentram seus esforços na análise do ambiente presente e, no máximo, recomendações de curto prazo. À exceção das organizações $\mathrm{C}$ e $\mathrm{H}$, todas as demais constroem suas análises com base em séries históricas e dados quantitativos. Nelas, ainda predomina do uso de fontes secundárias oriundas de empresas confiáveis e de fontes governamentais para fundamentar seus produtos. Ensina que o passado pode ser um indicador impreciso e perigoso na construção de inferências. 
Precisão - Segundo Ramos \& Moreti, Inteligência Competitiva: Aspectos Críticos na Empresa Brasileira (2008), para devida aplicação dos conceitos de IC, a informação deve ser gerada com qualidade e veracidade, sob o ponto de vista deste constructo; com exceção da empresa B, os entrevistados consideram os produtos de Inteligência Competitiva constantemente precisos. Na visão dos gestores, essa avaliação torna o conteúdo das análises mais confiáveis. O resultado reforça a ideia de que o uso de dados secundários de fontes confiáveis concede maior credibilidade aos documentos de IC. Em geral, as empresas acessam as mesmas fontes externas. Elas correlacionam essas informações aos próprios dados internos. No caso das empresas A, B e D, é comum comprar bases de dados privados para atender a uma demanda específica. Para os entrevistados da empresa A e D, a precisão induz os usuários a utilizarem os produtos nas decisões organizacionais, principalmente em situações que envolvam a análise da realidade atual, em que os dados secundários são capazes de traçar o perfil do ambiente vigente.

Eficiência dos Recursos - Para Fleisher e Bensoussan (2003), a eficiência é uma relação de custo e benefício, o custo de obtenção e análise dos dados não deve exceder os benefícios gerados. Nas empresas pesquisadas, exceto as empresas $\mathrm{Ce} \mathrm{H}$, cuja coleta de dados foi focada em fontes humanas, as outras organizações costumam empregar informações quantitativas. No que se refere ao uso de ferramentas ou sistemas para suporte à Inteligência Competitiva, a percepção dos usuários é que os instrumentos disponíveis são insuficientes (com exceção da empresa A). A falta de ferramentas é um desafio, pois elas tendem a gerar ganhos de velocidade e de capacidade analítica nas áreas de Inteligência. A maioria dos negócios pesquisados acessa setores internos e interage com os fornecedores e clientes. Quanto à falta de recursos para a atividade, somente as empresas $\mathrm{A}, \mathrm{C}$ e $\mathrm{G}$ entendem tê-los de forma plena. Porém, mesmo que eles pareçam escassos, os usuários pesquisados entendem que parte da responsabilidade de sensibilizar a empresa quanto à necessidade de mais recursos na atividade deve partir, exatamente, do setor que a promove.

Objetividade - Para Fleisher e Bensoussan (2003) as informações devem ser analisadas com objetividade sistêmica e com base na lógica racional, como mecanismo para evitar o viés cognitivo ou social predominante nas culturas organizacionais. A pesquisa aponta que em todas as empresas foi constatada a influência da cultura organizacional nos produtos de Inteligência. Porém, na percepção dos usuários, essa característica não é negativa e tende a gerar alinhamento da função à forma de fazer negócios da companhia. Quanto aos vieses dos analistas, os pesquisados não os notam nas análises de IC, exceto na empresa E, cujo posicionamento e recomendações estão presentes nos materiais. Em geral, quando os produtos são compostos es sencialmente por dados, eles são mais informativos e imparciais. Sobre a racionalidade, de acordo com os usuários, a área de Inteligência emprega processos lógicos na elaboração dos seus produtos. A lógica de raciocínio e o uso de dados norteiam tal percepção. Todavia, as empresas B e $\mathrm{H}$ utilizam a experiência de especialistas para sedimentar suas análises. O uso da intuição é bastante valorizado nestas empresas. Como as informações nãoestruturadas tendem a ser mais exclusivas, elas tendem a criar uma vantagem comparativa ante os demais agentes econômicos.

Utilidade - É preciso que o analista desenvolva produtos "essenciais de saber" e não os "interessantes de saber" para que atendam ou superem as necessidades do usuário-final (Fleisher \& Bensoussan, Strategic and Competitive Analaysis:Methods and Techniques for Analyzing Business Competition., 2003) e neste constructo somente a empresa C se destaca. A dificuldade de transformar as análises em ações corrobora essa visão e, novamente, apenas a empresa $\mathrm{C}$ atende o quesito. As demais enfrentam intensa dificuldade de fazer com que suas orientações se tornem ações da companhia. Nas entrevistas, a falta de visão de futuro justificou esta realidade. Além disso, as análises feitas por outros setores da empresa ganham espaço nas decisões, o que reduz a necessidade de uso da Inteligência quando seus produtos são simplesmente informativos. Na visão dos usuários, as unidades de IC estão mais focadas em seus materiais fáceis de entender do que em torná-los acionáveis. Quanto à Aderência, todos os usuários consideram que os relatórios de Inteligência Competitiva estão em conformidade com o que a empresa necessita. Mas, nas empresas C, D, Ge $\mathrm{H}$, os entrevistados indicam haver oportunidade de melhoria: os produtos de IC, mesmo que aderentes à realidade organizacional, não transcendem as informações explícitas nos dados e oferecem poucas inferências que criem valor ao negócio.

Oportunidade - As informações devem ser utilizadas no momento oportuno, sob risco de perder a utilidade para outros (Fleisher; Bensoussan, 2003; Fuld, 2007). Nas organizações analisadas, os entrevistados avaliam que os produtos de IC atendem o tempo necessário para a tomada de decisão e fornecem prazo suficiente para implantar o curso de ação recomendada. Contudo, o uso dos materiais no processo decisório ainda é limitado. Segundo os usuários das empresas B, E e F, as empresas, mesmo acessando um material objetivo, oportuno e preciso, ainda não estão preparadas para empregar essas análises de forma efetiva na tomada de decisão. Nas entrevistas, a percepção dos usuários é de que os produtos de Inteligência possuem um potencial analítico elevado, todavia são mais usados para justificar uma ação já realizada do que para direcionar novas decisões. Além disso, a atualidade das informações contidas nos produtos de IC foi avaliada 
como plenamente atendida por cinco das oito empresas entrevistadas (A, C, D, F e H).

\subsection{Integridade}

Ética - A ética é construída por um conjunto de valores, princípios e virtudes e devem orientar a coleta de dados em conjunto com a legalidade (Marcial, Costa \& Curvello, 2002; Cleland \& King, 1975; Clerc, 1997; Gomes; Braga, 2004). Nas organizações objeto da pesquisa foi apontando que o código de ética, estruturado e formalizado, não é considerado essencial para a disseminação da Ética na empresa. Os entrevistados o percebem como algo burocrático e que a divulgação dos princípios éticos é feita na companhia como um todo. Quanto ao sigilo dos dados, ain da que a maioria das organizações utilizem apenas informações publicáveis, os dados internos são confidenciais e, caso sejam divulgados, podem gerar danos à imagem e ao negócio. Esta percepção está presente na resposta dos usuários sobre a preocupação das empresas quanto aos riscos de uma possível conduta antiética de seus profissionais. Praticamente todas elas consideram a ausência de ética na conduta de seus colaboradores, uma falta grave que pode ocasionar desdobramentos negativos para a organização. Além disso, a maior parte das organizações pesquisadas usa de bases de dados pagas e lícitas, além de empregarem dados não estruturados de fornecedores e clientes. Tais informações tendem a criar maior valor agregado, pois são exclusivas e assimétricas.

Legalidade - A manutenção de atitude ética e legal distingue as organizações do comportamento de espionagem industrial (Marcial, Costa \& Curvello, 2002; Rodrigues, Miranda \& Crespo, 2010). A pesquisa aponta que o país ainda possui uma legislação de acesso e uso da informação diminuta. Devido à pequena projeção dessas normas, as empresas não se preocupam tanto com o domínio e a disseminação da legislação que rege a atividade de IC. As únicas empresas que apresentaram e atenção plena às regras foram a B e F. O usuário da empresa B enfatizou que a organização divulga constantemente aos seus profissionais, o modo como os dados devem ser obtidos e tratados. A maioria das companhias pesquisadas, exceto a empresa $\mathrm{F}$, tem áreas jurídicas que fornecem o apoio para que suas informações não causem dano ao negócio. Devido à existência dos departamentos jurídicos para os usuários, a temática da legalidade está mais vinculada a estas unidades do que a IC. Além disso, apenas as empresas A, F e Gavaliam que, caso seus produtos de IC fossem acessados por outros agentes econômicos, eles não criariam qualquer dificuldade. A justificativa pauta-se no uso de informações publicáveis. As outras possuem algum receio sobre o acesso aos dados das empresas, em especial quando empregam dados internos nas análises.

Transparência - As empresas devem priorizar a clareza e transparência das informações geradas pelas áreas de IC, quanto maior a visibilidade da área de IC melhor as interações com as outras áreas da organização, a prática da transparência proporciona a possibilidade do trabalho em rede (Sawka, 2000; Ramos \& Moretti, 2008). Esta pesquisa apontou que nas empresas A, D, E e $\mathrm{H}$, os produtos de IC são elaborados quase que exclusivamente dentro das equipes de Inteligência, nas empresas B, C, F e G, a interação com outros setores é intensa. Em geral, as áreas que contam com uma equipe menor tendem a buscar mais o apoio de outros setores. A acessibilidade aos profissionais de Inteligência foi considerada satisfatória por todos os entrevistados. Ela torna mais fácil a criação de redes internas e externas e a obtenção de informações em outros departamentos, o que reforça a tendência de que as unidades de IC precisam ser visíveis e transparentes. Quanto à comunicação, os usuários das empresas A, B, C e F a entendem como positiva. Para as empresas $\mathrm{G}$ e $\mathrm{H}$, há potencial de melhorá-la. Para os usuários, os produtos de IC cumprem, em grande parte, uma função informacional e não decisória, isto é, embora eles transmitam alinhamento com o uso estratégico das informações, internas e externas, não é tão claro o que estes produtos devem encerrar dentro da organização.

\subsection{Ass ociação da Acionabilidade com a Integridade}

Diante do resultado de cada atributo, foram construídos, para cada empresa, os valores referentes à Acionabilidade e à Integridade (Figura 1). Eles foram obtidos por meio da média simples dos fatores que compõem cada uma das dimensões. Além da posição das empresas em cada setor, a Matriz permite entender a direção que as áreas de IC precisam trilhar para tornar a Inteligência, de fato, efetiva. Para entender as características e comportamento em cada um dos setores do modelo, eles serão analisados, separadamente, nos tópicos a seguir. 


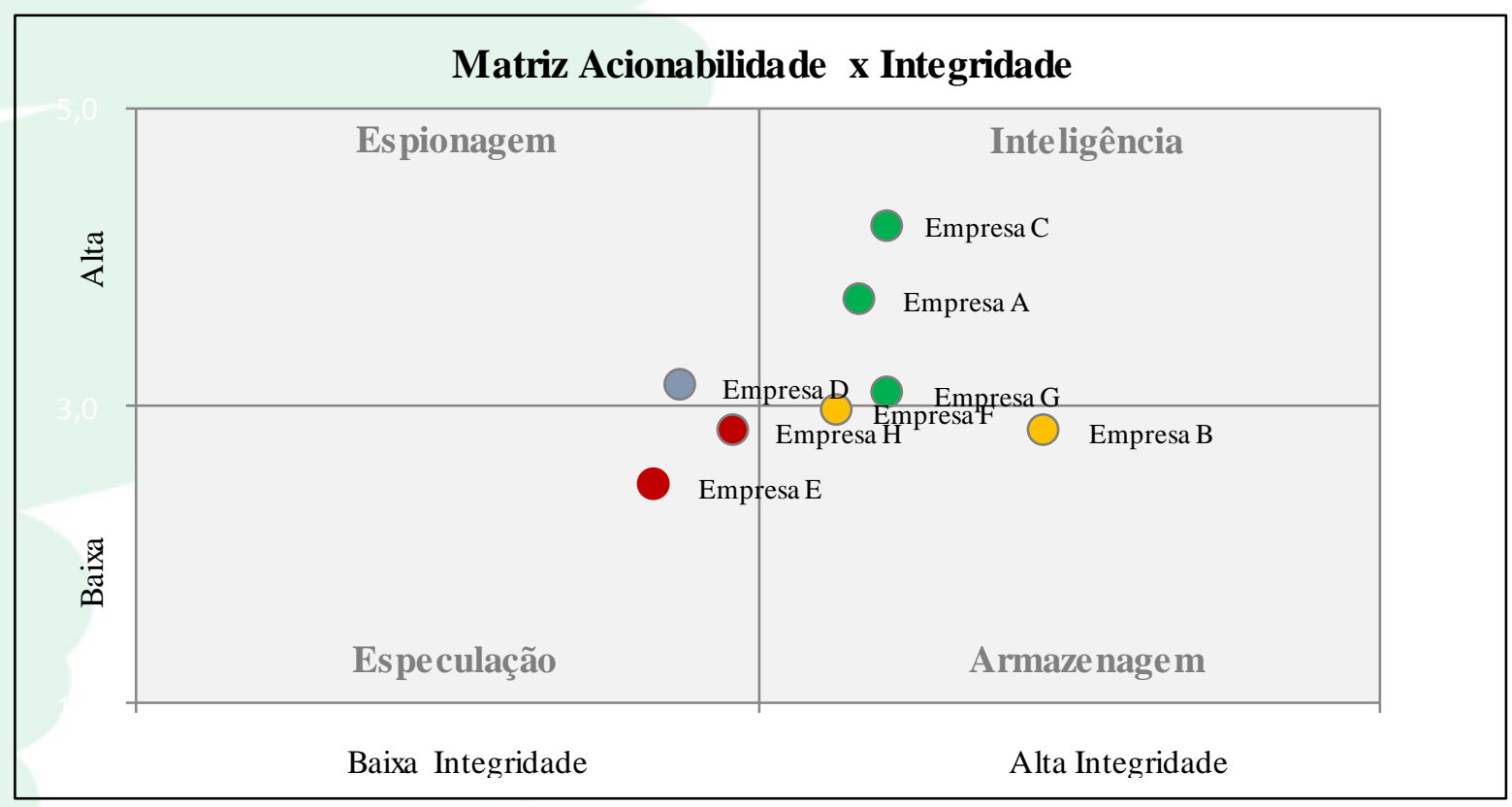

Figura 1 - Matriz Acionabilidade x Integridade Fonte: Elaborado pelo autor.

A classificação das organizações nos quadrantes da matriz é proveniente da média simples apurada pela avaliação do conjunto de atributos que compõem as dimensões Acionabilidade e Integridade; os valores estão apurados pelo questionário estruturado que se encontra no apêndice I. A cada conjunto de quatro perguntas do questionário, são definidos os critérios de avaliação dos atributos que compõem a Acionabilidade e a Integridade. Desta forma, pelos resultados de cada um dos atributos, foram construídos os valores referentes às dimensões Acionabilidade e Integridade, conforme apresentado no quadro 2.

\begin{tabular}{|c|c|c|c|c|c|c|c|c|}
\hline & A & B & C & D & E & F & G & H \\
\hline Acionabilidade & 3,71 & 2,83 & 4,21 & 3,13 & 2,46 & 2,96 & 3,08 & 2,83 \\
\hline Integridade & 3,33 & 3,92 & 3,42 & 2,75 & 2,67 & 3,25 & 3,42 & 2,92 \\
\hline
\end{tabular}

Quadro 4 - Médias do conjunto de atributos que compõem a Acionabiliade e Integridade Fonte: Elaborado pelo autor.

As empresas que apresentam média inferior a 3 nas dimensões Acionabiliade e Integridade, não conseguiram demonstrar pleno desenvolvimento no conjunto de atributos constitutivos das referidas dimensões, caracterizando por uma natureza mais informativa.

A matriz demonstra que a organizações $\mathrm{A}, \mathrm{C}$ e $\mathrm{G}$ mantiveram média alta para Acionabilidade e integridade. As organizações demonstraram capacidade plena de construção da área de Inteligência Competitiva. As organizações que obtiveram média alta para Acionabilidade e baixa para Integridade tiveram suas áreas de inteligência classificadas como de espionagem, o que pode ser observado para a empresa D. As organizações que não alcançaram média satisfatória para nenhum dos pilares tiveram suas áreas de inteligência classificadas como especulação, padrão percebido nas empresas $\mathrm{E}$ e $\mathrm{H}$. As companhias que tiveram média alta para Integridade e baixa para
Acionabilidade tiveram suas áreas de inteligência classificadas como de armazenagem, comportamento apresentado na matriz para as empresas B e F.

Setor Armazenagem (Marcial, Costa, \& Curvelo, Lícito versus Ético: Como as Ferramentas da Inteligência Competitiva Podem para a Boa Imagem Corporativa, 2002) - As empresas B e F estão nesse setor. Elas têm a dificuldade de utilizar os produtos de IC nas decisões. Para seus usuários, as informações contidas nos documentos são importantes, mas raramente se transformam em ação. O conteúdo dos materiais é 'interessante de saber' ao invés de 'útil de saber'. Na visão dos entrevistados, os conhecimentos se limitam a analisar o ambiente atual e a informar sobre séries históricas. Em ambos os casos, existe a percepção de Integridade dos processos, em especial na empresa B, cuja avaliação foi a mais positiva neste quesito. Nela, os usuários utilizam as análises para justificar projetos atuais. No caso da empresa F, as 
diretrizes internas engessam a função de IC, o que a torna muito parecida com uma biblioteca de dados. Foi apontada a existência de uma alta demanda por dados, mas eles são usados de forma superficial e às vezes ilustrativas.

Setor Especulação (Marcial, Costa, \& Curvelo, Lícito versus Ético: Como as Ferramentas da Inteligência Competitiva Podem para a Boa Imagem Corporativa, 2002) - Composto pelas empresas E e H, seus produtos de IC não transmite a confiabilidade e a segurança necessárias. Como nem sempre as análises estão fundamentadas em informações consistentes, eles tendem a emitir opiniões sem grande embasamento. Os materiais não garantem aos gestores a segurança de que eles precisam no processo decisório. Segundo o usuário da empresa $E$, parte da dificuldade de fazer a Inteligência acionável está no caráter generalista dos produtos. Eles não estão aderentes à necessidade dos gestores. Além disso, foi observado que a presença das empresas no setor deve-se à desatenção aos processos de construção das informações. Por exemplo, a empresa E não tem um Código de Ética que oriente sobre as normas em torno do acesso e tratamento das informações. No caso das duas companhias, não foi percebido, por seus usuários, o foco na divulgação das regulamentações tampouco na atualização das equipes de Inteligência Competitiva. Por fim, não foram identificadas atividades ilegais nas áreas de IC, o que reforça o porquê as empresas estão nesse setor, ou seja, por descuido com a Integridade e não devido a processos inadequados.

Setor Espionagem (Marcial, Costa, \& Curvelo, Lícito versus Ético: Como as Ferramentas da Inteligência Competitiva Podem para a Boa Imagem Corporativa, 2002) - A empresa D é a única neste setor. Ela destaca-se pela capacidade de seus produtos de IC serem utilizados pelos gestores em ações da empresa. Eles dispõem de análises, inferências e análises focadas no curto prazo, e orientam sobre o ambiente atual de negócios. Na percepção do usuário, ainda existe oportunidade de melhorar a visão de médio e longo prazo. Porém, como os recursos na atividade são reduzidos, os profissionais de Inteligência precisam focar em determinados aspectos para fazerem a atividade acontecer. Este processo faz com que a equipe não tenha tempo suficiente para ocupar-se com tarefas vistas como burocráticas, como a estruturação de um Código de Ética ou um estudo sobre a legislação vigente. A unidade suporta tais deficiências com auxílio de outras áreas, como o jurídico. Embora o nome da categoria possa carregar uma conotação negativa, a companhia realiza suas atividades de modo legal e ético. O nível baixo de Integridade se deve à exposição ao risco de imagem e negócio, ocasionado pela falta de conhecimento e disseminação restrita sobre as normas e diretrizes que devem reger a atividade de IC.

Setor Inteligência (Fleisher \& Bensoussan, 2003; Marcial, Costa \& Curvello, 2002) - Na visão dos usuários, as empresas A, C e G são capazes de efetivamente apoiarem as decisões. Suas áreas de IC são conhecidas como parte essencial do fornecimento de dados atuais e relevantes para o negócio. Na empresa $\mathrm{C}$, foi enfatizado que os relatórios de Inteligência apoiam as decisões, mas não são o único instrumento, e que, junto com as demais ferramentas, fornecem uma ação mais segura da empresa. Para o entrevistado da empresa $G$, há espaço para maior adoção dos materiais de IC no seu negócio. Nos três casos, a principal deficiência está na falta de conhecimento acerca das leis de uso da informação. Embora elas não tenham Códigos de Ética específicos, elas têm princípios que norteiam o comportamento dos seus profissionais. As empres as $\mathrm{Ce}$ Gse destacam pela visibilidade e pela construção coletiva dos produtos de Inteligência. Na visão dos usuários, dois desafios de suas empresas são o uso de fontes não-estruturadas e o desenvolvimento de ferramentas de suporte a IC. Na empresa A, a construção de dados, racional e lógica, reflete o uso intenso de séries históricas e informações quantitativas. Nota-se que os dados qualitativos de fontes humanas tendem a trazer conhecimentos únicos e assimétricos, que geram maior diferencial para o negócio.

\subsection{Limitações}

Este estudo, de natureza qualitativa, refere-se a uma etapa preliminar para validação e qualificação do modelo proposto para análise da associação da Acionabilidade e da Integridade em produtos de Inteligência Competitiva. Todavia, para generalizar o conhecimento nele obtido, seria necessário realizar outras etapas de pesquisas posteriores, de natureza qualitativa e também quantitativa, para a efetiva validação da matriz como uma solução científica de análise da Inteligência. Em nenhum momento da pesquisa se pretendeu expandir os conhecimentos aqui adquiridos para todo o universo de empresas com funções formais de IC. Ao contrário, os conhecimentos apresentados nos Resultados do Estudo são fundamentos para sedimentar o desenvolvimento de um novo cabedal de conhecimentos originais e orientados para o campo da Inteligência Competitiva no país.

\section{CONSIDERAÇÕES FINAIS}

A Matriz Acionabilidade $x$ Integridade (Fleisher; Bensoussan, 2003; Marcial; Costa; Curvello, 2002) indica a posição da função de IC ante as dimensões pesquisadas. O ideal é que cada empresa que se posicione nesta matriz busque quais são as causas que fazem com que a função de Inteligência Competitiva ocupe determinado espaço e quais atributos precisam para que ocupe a posição almejada dentro do modelo. 
Dentro das organizações pesquisadas, foi observado que os produtos de IC não são usados como fonte principal para a tomada de decisão, mas como instrumento complementar às demais ferramentas. Essa ideia retira da Inteligência a presunção de ser considerada a melhor alternativa para a empresa e a coloca no patamar de outras iniciativas que norteiam o processo de decisão. Além disso, os produtos de IC são usados como um informativo, consultados para defender uma ação já tomada. Na visão dos usuários, a Integridade ainda é percebida como uma necessidade da função enquanto a Acionabilidade é um estímulo que movimenta a Inteligência Competitiva rumo à criação de vantagem competitiva.

Uma contribuição desse trabalho, tanto em termos teóricos quanto em termos gerenciais, se refere à associação entre os pilares acionabilidade e integridade na construção de modelos de inteligência competitiva. Ele permite uma nova abordagem sobre os dois pilares da IC - Acionalibilidade e Integridade bem como pode ser útil aos gestores para o acompanhamento das atividades e projetos de IC desenvolvidos dentro das organizações.

Nesse trabalho, é possível observar que a IC pode contribuir para a construção das estratégias organizacionais; os conceitos de Acionabilidade e Integridade demonstraram similaridades conceituais com os modelos estratégicos tradicionais. A orientação dada pelo sistema FAROUT (Fleisher \& Bensoussan, Strategic and Competitive Analaysis:Methods and Techniques for Analyzing Business Competition., 2003)de visão orientada para o futuro, precisão, eficiência de recursos, objetividade, utilidade e oportunidade são também apresentados pelos modelos estratégicos, com denominações distintas, mas muitas características conceituais similares.

É importante ressaltar que, como todo estudo, essa pesquisa tem limitações. Por exemplo, os resultados aqui descritos não são generalizáveis para todo o universo de empresas com IC. O acesso a um único gestor por organização restringe o alcance do estudo. Se ele é a favor ou contra a atividade de Inteligência em sua empresa, provavelmente essa tendência pode ter surgido numa ou noutra resposta. Quando se entrevista mais de umusuário, a tendência é que tais vieses sejam mais difíceis de acontecerem. A subjetividade do método afeta o estudo à medida que o pesquisador é quem determina o grau de cada variável. É sob seu ponto de vista que são posicionadas as respostas sobre a percepção do usuário. Embora todo pesquisador científico busque sempre a isenção e a imparcialidade, é praticamente impossível retirar da análise sua herança cultural, seus vícios de entendimento e sua visão sistêmica.

Não obstante, sugere-se a seguir alguns próximos passos. Um estudo de mesma natureza pode ser realizado dentro de segmentos econômicos específicos, pois cada setor tende a apresentar dinâmicas diferentes. Assim, o recorte por atividade econômica pode resultar numa informação mais precisa sobre a atividade de IC. Da mesma forma, recomendase a categorização regional. Sugere-se ainda que seja construído um instrumento quantitativo para avaliação dessas dimensões, forma complementar de tornar mais assertiva e precisa a avaliação da função de IC nas organizações. A construção desse produto tende a tornar a avaliação mais simples, generalizável e menos subjetiva, amenizando algumas limitações que o estudo qualitativo não foi capaz de absorver por completo.

Recorda-se que a iniciativa de se estudar um campo tão pouco explorado na realidade organizacional brasileira busque estimular a criação de um novo cabedal de conhecimentos sobre a Inteligência Competitiva no país. Espera-se que estudos como esse possam catalis ar a função de IC nas empresas nacionais e, assim, torná-la uma atividade relevante para tomada de decisões mais assertivas, para a redução da exposição aos riscos por parte das empresas e para expandir exponencialmente a competitividade do negócio.

\section{REFERÊNCIAS}

Associação Brasileira dos Analistas de Inteligência Competitiva, A. (11 de 2011).

http://www.abraic.org.br/v2/glossario.

Barclay, R., \& Kaye, S. (2000). Millennium Intelligence: Understanding and Conducting Competitive Intelligence in the Digital Age. New Jersey: Cyberage Books, 81-195.

Bouthillier, F., \& Shearer, K. (2003). Assessing Competitive Intelligence Sofware: A Guide to Evaluating CI Tecnology. Ney Jersey: Information Today, 187.

Cleland, D., \& King, W. (1975). Competitive Business Intelligence System. Business Horizons, 19-28.

Clerc, P. (1997). World Information Report. Paris: UNESCO.

Comai, A., \& Millán, J. (2006). Mapping and Anticipating the Competitive Lanscape. Barcelona: EMECON Ediciones, 145.

Combs, R., \& Moorhead, J. (1992). The Competitive Intelligence Handbook. Metuchen: Scarecrow Press, 197.

Crane, A. (2005). In The Company of Spies: When Competitive Intelligence Gathering Becomes Industrial Espionage. Business Horizons, 233-240. 
Cruz, C., \& Ribeiro, U. (2003). Metodologia Científica: Teoria e Prática. Rio de Janeiro: Axcel Books.

Degent, R. (1986). A Importância da Estratégia e o Funciomamento do Serviço de Inteligência Empresarial. Revista de Administração de Empresas, 77-83.

Fernandez, M., \& Lana, R. (2008). Inteligência Competitiva: Uma Nova Ferramenta para o Empreendedoris mo. Revista de Administração, Contabilidade e Economia Unoesc., 149-166.

Fleisher, C., \& Bensoussan, B. (2003). Strategic and Competitive Analaysis:Methods and Techniques for Analyzing Business Competition. New Jersey: Prenctice Hall.

Fleisher, C., \& Bensoussan, B. (2007). Business and Competitive Analysis: Effevtive Application ofNew and Classic Methods. New Jersey: Prentice Hall.

Fleisher, C., Wright, S., \& Tindale, R. (2007). Bibliography and Assessment of Key Competitive Inteligence Scholarship: Part 4 . Jornal of Competitive Intelligence and Management, 32-92.

Fleisher, C., Wright, S., \& Trindade, R. (2010). Competitive Intelligence Analysis Failure: Diagnosing Individual Level Causes and Implementing Organizational Level Remedies. Journal of Strategic Maketing, 553-572.

Fuld, L. (1995). The New Competitor Intelligence. New York: Wiley.

Fuld, L. (2007). Inteligência Competitiva: Como se Manter à frente dos movimentos da Concorrência e do Mercado. Rio de Janeiro: Elsevier.

Ganesh, U., Miree, C., \& Prescott, J. (2003). Competitive Intelligence Field Research: Moving the Field Forward by Stting a Research Agenda. Journal of Competitive Intelligence and Management, 1-12.

Gilad, B. (2004). Early Warning: Using Competitive Intelligence to Antecipate Market Shifts, Control Risk, and Create a Powerful Strategies. AMACON, 268.

Gilad, B. (2011). Strategy Without Intelligence, Intelligence Without Strategy. Business Strategy, 4-11.

Gomes, E., \& Braga, F. (2004). Inteligência Competitiva: Como Transformar Informação em um Negócio Lucrativo. Rio de Janeiro: Elsevier.

Gonzalez, I. V., \& Campos, F. C. (2015). Proposta de Modelo Conceitual de Formação de Estratégia de
Negócio a partir da Integração da Aprendizagem Organizacional e a Gestão da Inovação. UNIFASC, 473-493.

Herring, J. (1996). Measuring the Effectiveness of Competitive Intelligence. SCIP.

Hodges, C. (2005). Competitive Intelligence: Overview Feeding the Competitive Analysis Process. ASQ World Conference on Quality and Improvement Proceedings.

Hohhof, B. (2002). O Mercado da Tecnologia da Informação. In: MILLER, Jerry. O Milênio da Inteligência Competitiva. Porto Alegre: Bookman, 157179.

Juhari, A., \& Stephens, D. (2006). Tracing the Origins of Competitive Intelligence Throughout History. Journal of Competitive Intelligence and Mangement, 61-81.

Kelley, W. (1968). Marketing Intelligence: The Management of Marketing Information. London: Staples Press, 248.

Lapponi, J. (2003). Modelagem Financeira com Excel. Rio de Janeiro: Elsevier.

Lesca, H., Freitas, H., \& Cunha, M. (1996). Como Dar um Senso Útil às informações Dispersas para Facilitar a Decisão e Ações dos Dirigentes: O Problema Crucial da Inteligência Competitiva Através da Construção de um "Puzzle". . Séries Documentos para Estudos, PPGA/UFRGS, 1-12.

Liu, Y. (2013). Sustainable competitive advantage in turbulent business environments. International Journal of Production Research, 2821-2841.

Malhorta, N. (2011). Pesquisa de Marketing: Uma Orientação Aplicada. Porto Alegre: Bookman.

Marcial, E., Costa, A., \& Curvelo, J. (2002). Lícito versus Ético: Como as Ferramentas da Inteligência Competitiva Podem para a Boa Imagem Corporativa. Iteligência Empresarial, 23-29.

Martinet, B., \& Marti, Y. (1995). L'Intelligence Économique: Les Yeuxetles Oreilles de I'entreprise. Paris.

Miller, J. (2002). O Milênio da Inteligência Competitiva. Porto Alegre: Bookman.

Pereira, F., Mafra, R. d., \& Ricardo, V. D. (2016). Análise do Ciclo da Inteligência Competitiva em Arranjos Produtivos Locais: Estuturação do Bureau de Inteligência do APL de Software de Belo Horizonte. Revista de Inteligêcia Competitiva, 139-164. 
Pereira, J., \& Hanashiro, D. (2010). Ser ou não ser favorável às práticas de diversidade? Eis a questão. Fonte: http://dx.doi.org/10.1590/S141565552010000400007.

Prescott, J. (1999). The Evolution of Competitive Intelligence. . Association of Proposal Management Profissional (APMP), 37-52.

Ramos, D., \& Moreti, C. (2008). Inteligência Competitiva: Aspectos Críticos na Empresa Brasileira. Integração, 6-16.

Ramos, D., \& Moreti, C. (2008). Inteligência Competitiva: Aspectos Críticos na Empresa Brasileira. Integração, 6-16.

Rodrigues, A., Miranda, C., \& Crespo, I. (2010). Inteligência Competitiva em Unidades e Informação: Ética e Gestão. Revista Digital de Biblioteconomia e Ciência da Informação, 53-71.

Sammon, W., Kurland, M., \& Splitalnic, R. (1984). Business Competitor Intelligence: Methods for Collecting, Organizing and Using Information. New York: John Wiley \& Sons.

Sawka, K. (2000). Millennium Intelligence: Understanding and Conducting Competitive
Intelligence in the Digital Age. New Jesey : Cyberage Books.

SCIP, S. a. (05 de 06 de 2012)

http//www.scip.org/resources/content.cfm?/itemnumber $=601 \&$ navItemnumber $=533 \mathrm{~d}$.

Søderberg, A.-M. (2015). Recontextualising a strategic concept within a globalising company:. The International Journal of Human Resource Managemen, 231-257.

Tarapanoff, K. (2001). Inteligência Organizacional Competitiva. Brasilia: UNB.

Toledo, L.; Toledo, L. (2007). Sistema de Inteligência Competitiva: Um Estudo de Caso no Setor de Telecomunicações. Revista FAE, 1-18.

Triviños, A. (1987). Intordução à Pesquisa em Ciências Sociais: A Pesquisa Qualitativa em Educação. São Paulo: Atlas.

Yap, C., \& Rashid, M. (2 de April de 2011). Acquisitio and Strategic use of competitive intelligence. Journal of Library \& Information Science, pp. 125-136.

Zangoueinezhad, A., \& Moshabaki, A. (2008). The Role of Structural Capital on Competitive Intelligence. Industrial Management \& Data Systems, 262-280. 